\title{
Delayed Subarachnoid Hemorrhage after Cardiopulmonary Resuscitation: Case Report and Literature Review
}

\author{
Qitian Ou and Miaoyun Wen* \\ Guangdong General Hospital, Guangdong Academy of Medical Sciences, Guangzhou 510080, China
}

\begin{abstract}
We report here a case of a 54-year-old man who developed subarachnoid hemorrhage following cardiopulmonary resuscitation. Both computed tomography scans performed respectively within $24 \mathrm{~h}$ and on day 3 indicated a normal physical condition. The computed tomography scan conducted 7 days after the cardiopulmonary resuscitation revealed diffuse cerebral edema and subarachnoid hemorrhage. The existence of blood in cerebrospinal fluid was confirmed by lumbar puncture. We propose that ischemia/reperfusion response plays an important role in the development of post-resuscitation subarachnoid hemorrhage.
\end{abstract}

Introduction

Cardiac arrest is one of the leading causes of death. ${ }^{1}$ According to previous reports, the hospital mortality rate of cardiac arrest ranges from $50 \%$ to $71 \%{ }^{2,3}$ Apart from those immediate pathological changes resulting from cardiac arrest and cardiopulmonary resuscitation (CPR), other complicated pathophysiological changes occur during the post-cardiac arrest period. ${ }^{4}$ This period also comprises some neurological complications as well, such as hypoxic-ischemic encephalopathy. However, subarachnoid hemorrhage $(\mathrm{SAH})$ has been rarely reported as a delayed complication of CPR. ${ }^{5,6}$ We report herein a case of SAH as a complication of $\mathrm{CPR}$ and present our analysis of its mechanism.

\section{Case report}

A 54-year-old man presented to a local hospital, having a medical history of pulmonary embolism and deep vein thrombosis, and who was currently receiving anticoagulant therapy of rivaroxaban. He complained chest tightness, shortness of breath, and hemoptysis that had occurred for about 3 weeks. On the same day, he developed heart failure and was admitted to the Intensive Care Unit. His hemodynamics collapsed suddenly and the heart rate was

Keywords: Subarachnoid hemorrhage; Cardiopulmonary resuscitation; Reperfusion injury; Pseudo-subarachnoid hemorrhage.

Abbreviations: CPR, cardiopulmonary resuscitation; CT, computed tomography; $\mathrm{SAH}$, subarachnoid hemorrhage.

Received: January 22, 2019; Revised: April 14, 2019; Accepted: April 24, 2019

*Correspondence to: Miaoyun Wen, Guangdong General Hospital, Guangdong Academy of Medical Sciences, No. 106 Zhongshan 2nd Rd, Yuexiu Qu, Guangzhou 510080, Guangdong, China. E-mail: wenmiaoyun041105@163.com

How to cite this article: Ou Q, Wen M. Delayed Subarachnoid Hemorrhage after Cardiopulmonary Resuscitation: Case Report and Literature Review. Exploratory Research and Hypothesis in Medicine 2019;4(2):39-42. doi: 10.14218/ ERHM.2019.00003 extremely slow the day after his admission. CPR was initiated as soon as the staff identified the abnormal condition and lasted for about $20 \mathrm{~m}$ until spontaneous cardiac activities returned and satisfactory hemodynamics were obtained. However, a coma persisted. Computed tomography (CT) scan of the brain was performed $3 \mathrm{~h}$ after the CPR and repeated 3 days later. Both of the two pictures obtained indicated a normal physical condition (Fig. 1). The use of rivaroxaban was not interrupted at any time during this period.

The patient was transferred to our institution on the 7 th day after his admission to the local hospital. Upon his admission to our institution, the vital signs were as follows: blood pressure of $110 / 60$ $\mathrm{mmHg}$ (norepinephrine at $0.4 \mu \mathrm{g} / \mathrm{kg} / \mathrm{m}$ ); heart rate of $60 \mathrm{~min}^{-1}$; and body temperature of $39^{\circ} \mathrm{C}$. Physical examination showed that the patient was in a deep coma, and the pupillary light reflex was absent. The laboratory results were as follows: international normalized ratio of 1.32; activated partial thromboplastin time of 49.5 $\mathrm{s}$; platelet count of $90 \times 10^{9} / \mathrm{L}$; D-dimer of $>20000 \mathrm{ng} / \mathrm{mL}$; Nterminal B-type natriuretic peptide concentration of $7460 \mathrm{pg} / \mathrm{mL}$; and lactic acid of $10 \mathrm{mmol} / \mathrm{L}$. Liver function and renal function markers indicated slight impairment.

The CT scan conducted in our institution, at 7 days after the CPR, revealed that there was diffuse cerebral edema and hyperdensity in the sulcus and ventriculus quartus cerebri (49-52 Hounsfield units) (Fig. 1). Lumber puncture indicated the existence of blood in cerebrospinal fluid (Fig. 2). Therefore, the patient was diagnosed with SAH. CT-angiography of the pulmonary arteries revealed small embolisms in the branches of the right pulmonary artery. We suspected that pulmonary embolism might be the cause of the cardiac arrest. On the 8th day after CPR, the patient was in a profound coma. Since the patient's condition was irreversible, his family withdrew his treatment and transferred him back to the local hospital.

Discussion

It is known that hypoxemia, ischemia, and reperfusion are the 


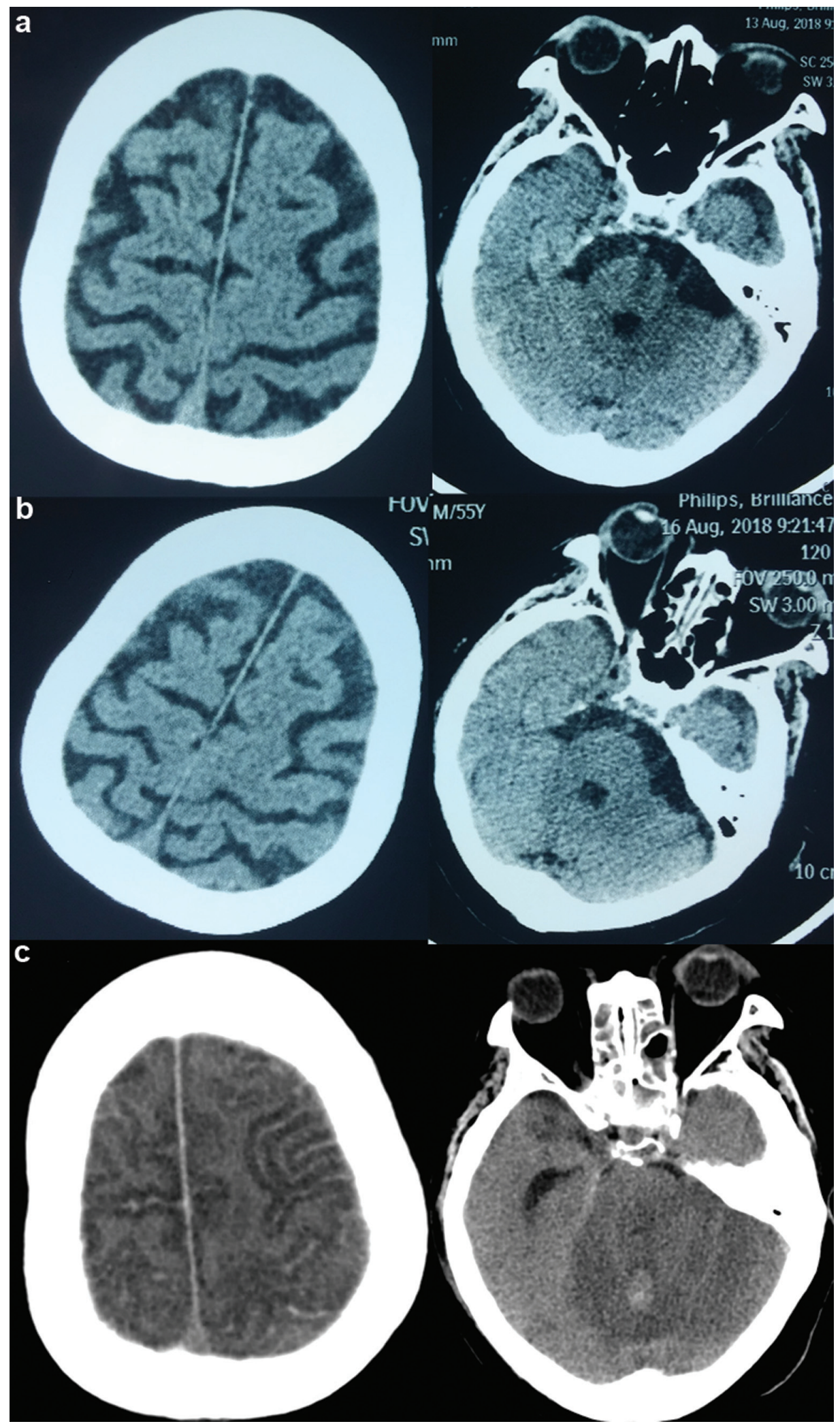

Fig. 1. Exemplary images of matching slice plains in the non-enhanced CT scan. CT scan of the head preformed $3 \mathrm{~h}(\mathrm{a})$ and 3 days (b) after the CPR indicated a normal physical condition, while the scan conducted 7 days after the CPR (c) revealed diffuse cerebral edema and hyperdensity in the sulcus and ventriculus quartus cerebri (49-52 Hounsfield units). Abbreviations: CPR, cardiopulmonary resuscitation; CT, computed tomography. 


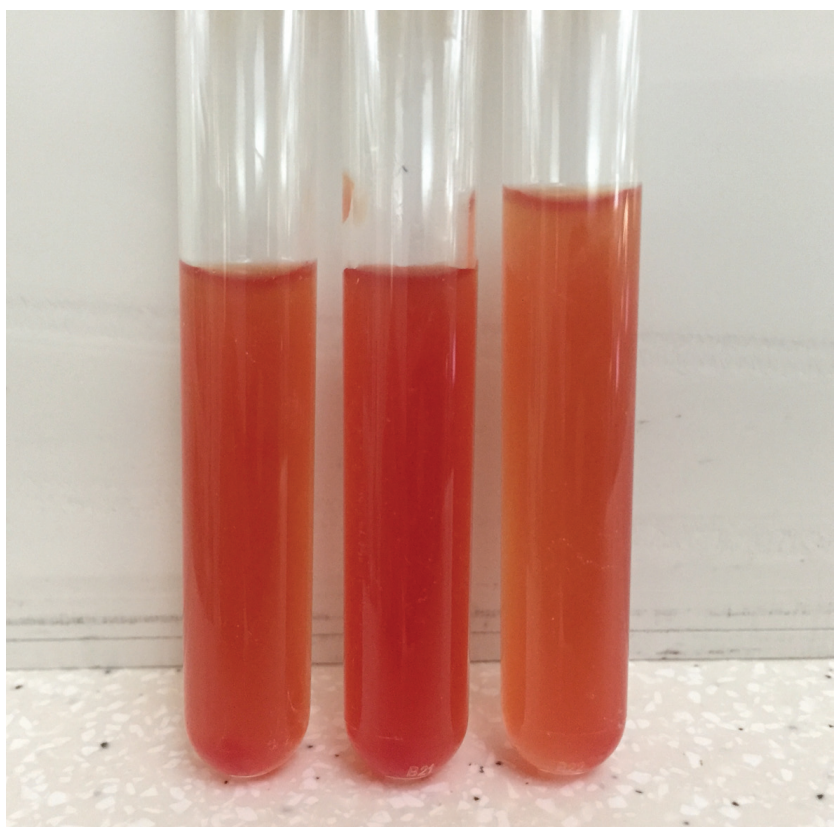

Fig. 2. Cerebrospinal fluid obtained 7 days after CPR. From left to right: the $1^{\text {st }}, 2^{\text {nd }}$ and the $3^{\text {rd }}$ tube of cerebrospinal fluid. Abbreviation: CPR, cardiopulmonary resuscitation.

main pathophysiological processes that occur during cardiac arrest and resuscitation, and can cause damage to multiple organs (circu). Brain injury, myocardial dysfunction, and the systemic ischemia/reperfusion response are the major symptoms that present during the post-arrest period. Among them, brain injury is a cause of death after resuscitation. Neurological complications of CPR mainly include hypoxic-ischemic encephalopathy, infarcts, and brain edema. ${ }^{4} \mathrm{SAH}$ as a complication of CPR has been rarely reported (Table $1^{5,6}$ ).

Spontaneous SAH is usually caused by aneurysms and arteriovenous malformations. Major pathophysiological changes secondary to SAH include increased intracranial pressure, cerebrovascular spasm, and hydrocephalus. ${ }^{7}$ CT scan is highly sensitive in detecting hemorrhage at the early stage, with an accuracy of more than $90 \% .^{7}$ Blood in the cerebrospinal fluid revealed by lumber puncture helped us to make the diagnosis of SAH for the patient reported on herein

Pulmonary embolism and heart failure were considered the causes of the patient's cardiac arrest. However, absence of symptoms of SAH, such as headache and syncope, and the normal condition indicated by $\mathrm{CT}$ brain scan films can lead doctors to rule out the possibility of SAH, though it is a common cause of cardiac arrest. CT scan and lumber puncture actually established the diagnosis of SAH in our case, which occurred between the 3rd and the 7th day after CPR.

As for the causes of SAH, we believe that ischemia/reperfusion response played an important role in the development of postresuscitation SAH in our patient. The persistent coma after resuscitation suggested the existence of cerebral hypoxia and ischemia. Cerebrovascular endothelial function and autoregulation were impaired in the hypoxic and ischemic phase. During the initial reperfusion, excessive oxygen could have exacerbated endothelial injuries by producing more free radicals and mitochondrial injury. Delayed brain edema that had occurred days after the cardiac arrest was revealed in the CT scan, and it seems to be the consequence of severe ischemic neurodegeneration. ${ }^{4}$ Impaired endothelium and delayed brain hyperemia played a role in establishment of a bleeding cascade, and finally led to SAH. In addition, the use of rivaroxaban might have been a contributing factor in the bleeding cascade. Cerebral aneurysm might be another potential cause of SAH. However, the patient's relatives refused another CT angiography. Therefore, we are not sure whether cerebral aneurysm played a role.

Pierre et $a l .{ }^{5}$ reported a case of early-onset SAH which happened immediately after CPR, but the authors could not convincingly rule out the possibility that the cardiac arrest had resulted from SAH. Whether increased intracranial pressure and central venous pressure during $\mathrm{CPR}$ can lead to $\mathrm{SAH}$ remains unknown.

The phenomenon of "pseudo-SAH" has been recognized. ${ }^{8-16}$ Non-enhanced CT scan performed on patients with "pseudo-SAH" reveals high-attenuation areas along the sulci and/or basal cisterns, which indicate $\mathrm{SAH}$, but lumbar puncture or autopsy results indicate no blood. ${ }^{9}$ Pseudo-SAH usually occurs in patients with severe cerebral edema. ${ }^{9,11}$ Explanations for this phenomenon include narrowing or complete collapse of the hypodense cerebrospinal fluid spaces, increased hypodensity of the adjacent brain, and vessel congestion. ${ }^{8}$ The CT values of high-attenuation areas in patients with pseudo-SAH are usually lower than 42.0 Hounsfield units ${ }^{11}$ and are well below the expected attenuation values of SAH, typically ranging from 60 to 70 Hounsfield units. ${ }^{9}$ However, in some particular types of pseudo-SAH, a relatively high $\mathrm{HU}$ value of

Table 1. Prior cases/reports about subarachnoid hemorrhage after cardiopulmonary resuscitation

\begin{tabular}{|c|c|c|c|c|}
\hline Authors & $\begin{array}{l}\text { Year of } \\
\text { publication }\end{array}$ & Brief summary & Similarities & Differences \\
\hline $\begin{array}{l}\text { Gueugniaud } \\
\text { PY, et al. } 5\end{array}$ & 1987 & $\begin{array}{l}\text { A } 40 \text {-year-old man with no previous } \\
\text { record of cardiac disease suddenly } \\
\text { collapsed. A profound coma } \\
\text { persisted after CPR, and SAH was } \\
\text { then confirmed by lumber puncture. }\end{array}$ & $\begin{array}{l}\text { The diagnosis of SAH } \\
\text { was made according } \\
\text { to lumber puncture. }\end{array}$ & $\begin{array}{l}\text { The clinical picture was clear in this } \\
\text { case. SAH occurred immediately } \\
\text { after the CPR. The patient had } \\
\text { good neurologic outcome. }\end{array}$ \\
\hline $\begin{array}{l}\text { Lowenthal } \\
\text { A, et al. }{ }^{6}\end{array}$ & 2004 & $\begin{array}{l}\text { A case of a } 20 \text {-year-old man who } \\
\text { developed cardiac arrest and } \\
\text { received CPR. A lumbar puncture } \\
\text { performed } 24 \text { h later was normal. } \\
\text { The contrast-enhanced CT scan } \\
\text { repeated } 5 \text { days after the initial } \\
\text { collapse demonstrated SAH. }\end{array}$ & $\begin{array}{l}\text { SAH occurred several } \\
\text { days after the CPR. Severe } \\
\text { brain edema was revealed } \\
\text { on the final CT scan, in } \\
\text { addition to hyperdensity } \\
\text { in the } \\
\text { sulcus. }\end{array}$ & $\begin{array}{l}\text { The patient was previously healthy and } \\
\text { not treated with thromboembolism } \\
\text { prophylaxis. The diagnosis of SAH was } \\
\text { made according to contrast-enhanced } \\
\text { CT instead of lumber puncture. }\end{array}$ \\
\hline
\end{tabular}

Abbreviations: $\mathrm{CPR}$, cardiopulmonary resuscitation; $\mathrm{CT}$, computed tomography; $\mathrm{SAH}$, subarachnoid hemorrhage. 
52-62 has been reported. ${ }^{10}$ In our case, the CT values of the hyperdensity in the sulcus and ventriculus quartus cerebri were lower than those of fresh blood in typical SAH. Brain edema existence and CT scan reminded us that pseudo-SAH should not be ruled out, though it was proved to be a true SAH ultimately. CT values of high-attenuation areas may be less reliable in differentiating $\mathrm{SAH}$ from pseudo-SAH. Lumbar puncture should be performed, especially on patients with SAH signs and cerebral edema.

\section{Conflict of interest}

The authors declare there are no conflicts of interest regarding the publication of this paper.

\section{Author contributions}

Conception/design of the research and critical revising of the manuscript (MW), acquisition and analysis of the clinical data, and manuscript drafting (QO).

\section{References}

[1] Monsieurs KG, Nolan JP, Bossaert LL, Greif R, Maconochie IK, Nikolaou $\mathrm{NI}$, et al. European resuscitation council guidelines for resuscitation 2015: Section 1. Executive summary. Resuscitation 2015;95:1-80. doi:10.1016/j.resuscitation.2015.07.038.

[2] Nadkarni VM, Larkin GL, Peberdy MA, Carey SM, Kaye W, Mancini ME, et al. First documented rhythm and clinical outcome from in-hospital cardiac arrest among children and adults. Jama 2006;295(1):50-57. doi:10.1001/jama.295.1.50.

[3] Nolan JP, Laver SR, Welch CA, Harrison DA, Gupta V, Rowan K. Outcome following admission to UK intensive care units after cardiac arrest: a secondary analysis of the ICNARC Case Mix Programme Database. Anaesthesia 2007;62:1207-1216. doi:10.1111/j.13652044.2007.05232.x.

[4] Neumar RW, Nolan JP, Adrie C, Aibiki M, Berg RA, Böttiger BW, et al. Post-cardiac arrest syndrome: epidemiology, pathophysiology, treatment, and prognostication. A consensus statement from the International Liaison Committee on Resuscitation (American Heart Associa- tion, Australian and New Zealand Council on Resuscitation, European Resuscitation Council, Heart and Stroke Foundation of Canada, InterAmerican Heart Foundation, Resuscitation Council of Asia, and the Resuscitation Council of Southern Africa); the American Heart Association Emergency Cardiovascular Care Committee; the Council on Cardiovascular Surgery and Anesthesia; the Council on Cardiopulmonary, Perioperative, and Critical Care; the Council on Clinical Cardiology; and the Stroke Council. Circulation 2008;118(23):2452-2483. doi:10.1161/CIRCULATIONAHA.108.190652.

[5] Gueugniaud PY. Subarachnoid hemorrhage: a complication of CPR? Crit Care Med 1987;15:284-285.

[6] Lowenthal A, Maimon N, Waldman S, Almog Y. Sub-arachnoid hemorrhage following cardiopulmonary resuscitation. Resuscitation 2004;63:221-223. doi:10.1016/j.resuscitation.2004.05.015.

[7] Macdonald RL, Schweizer TA. Spontaneous subarachnoid haemorrhage. Lancet 2017;389(10069):655-666. doi:10.1016/S01406736(16)30668-7.

[8] Coulier B. Pseudo-subarachnoid hemorrhage. J Belg Soc Radiol 2018;102(1):32. doi:10.5334/jbsr.1509.

[9] Given CA 2nd, Burdette JH, Elster AD, Williams DW 3rd. Pseudo-subarachnoid hemorrhage: a potential imaging pitfall associated with diffuse cerebral edema. AJNR Am J Neuroradiol 2003;24(2):254-256.

[10] Patzig M, Laub C, Janssen H, Ertl L, Fesl G. Pseudo-subarachnoid haemorrhage due to chronic hypoxaemia: case report and review of the literature. BMC Neurol 2014;14:219. doi:10.1186/s12883-0140219-7.

[11] Yuzawa H, Higano S, Mugikura S, Umetsu A, Murata T, Nakagawa $A$, et al. Pseudo-subarachnoid hemorrhage found in patients with postresuscitation encephalopathy: characteristics of CT findings and clinical importance. AJNR Am J Neuroradiol 2008;29(8):1544-1549. doi:10.3174/ajnr.A1167.

[12] Agha A, Al-Hakami M. A case report of pseudo-subarachnoid hemorrhage. Maedica (Buchar) 2011;6(3):210-212.

[13] Chute DJ, Smialek JE. Pseudo-subarachnoid hemorrhage of the head diagnosed by computerized axial tomography: a postmortem study of ten medical examiner cases. J Forensic Sci 2002;47:360-365.

[14] Misra V, Hoque R, Gonzalez-Toledo E, Kelley R, Minagar A. Pseudosubarachnoid hemorrhage in a patient with acute cerebellar infarction. Neurological research 2008;30:813-815. doi:10.1179/1743132 $08 \times 341021$.

[15] Yasar Tekelioglu U, Demirhan A, Akkaya A, Gurel K. Pseudo-subarachnoid hemorrhage and death after a bee sting. Medicinski glasnik 2013;10:182-185.

[16] Yokota H, Yokoyama K, Nakase H. Spontaneous intracranial hypotension with pseudo-subarachnoid hemorrhage. Acta Neurol Belg 2016;116:643-644. doi:10.1007/s13760-016-0623-4. 